\title{
Gamification and Its Application in Social Network Implementation
}

\author{
Ibrahim Omara \\ Department of Mathematics and Computer Science, Faculty of Science, Menoufia University, Egypt. \\ i_omara84@yahoo.com \\ 0000-0003-3243-990X
}

\begin{tabular}{|c|c|}
\hline Article History & Abstract \\
\hline $\begin{array}{l}\text { Article Submission } \\
21 \text { February } 2021 \\
\text { Revised Submission } \\
18 \text { March } 2021 \\
\text { Article Accepted } \\
22 \text { May } 2021 \\
\text { Article Published } \\
30 \text { June } 2021\end{array}$ & $\begin{array}{l}\text { In this communication strategy, ideal audiences that are perceived to yield an effective } \\
\text { influence of the stakeholders include national security or intelligence groups, as well as } \\
\text { external firms that engage in regular monitoring of user information systems in } \\
\text { collaboration with Visa's internal group of experts. Indeed, the role of the national } \\
\text { intelligence group(s) lies in addressing potential legal liabilities that could arise from } \\
\text { any customer complaints relating to communication failures or lapses when malicious } \\
\text { activities are detected. Similarly, the national intelligence group acts as a regulator to } \\
\text { check trends in Visa Inc.'s conformity to standards shaping the state of communication } \\
\text { about user information (in terms of frequency) and advising about some of the emerging } \\
\text { technologies or platforms that ought to be incorporated to foster inclusivity and reach } \\
\text { out to as many customer bases as possible. On the other hand, external firms } \\
\text { responsible for regular monitoring of user information will play the role of examining } \\
\text { some of the strengths of the communication strategies outlined and advising about } \\
\text { possible improvements that could be made to avoid lapses regarding the duration and } \\
\text { frequency of updates to the customers. It is also worth noting that the general public } \\
\text { forms another audience group that the formulated strategy seeks to involve because this } \\
\text { group plays a significant role of airing views about possible improvements that could } \\
\text { be made to the company's current communication goals. An ideal communication } \\
\text { platform through which views from members of the public could be received and } \\
\text { enacted accordingly is the social media, a trend that prompts Visa to have open forums } \\
\text { from which these members could be allowed to channel their views about the merits and } \\
\text { demerits accruing from the communication goals and their eventual implementation. } \\
\text { Kevwords: Social Network, Gamification }\end{array}$ \\
\hline
\end{tabular}

\section{Introduction}

The implementation and analysis of social networks accounts for sector reliance from businesses, marketers, and organizations. Company analysis and policy implementation are also responsible for the drive and measure of consumer behavior (Deterding, Dixon, Khaled \& Nacke, 2011). Indeed, gamification becomes a key element that mobile service providers adopt; perceived to be the ideal strategy towards online marketing in which business products and services flow in the supply chain. Zichermann and Cunningham (2011) document that gamification is a game element application within non-gaming contexts. The application aids in the motivation and influencing of user behaviors. Therefore, gamification builds brand loyalty in the business contexts and mobile applications, achieved through the creation of dynamic and engaging interactions. In particular, the purpose of gamification is to incorporate game elements in non-game contexts to ensure that the users of certain products gain access to the products by online means while participating in games. The eventuality is that, information regarding 
he company products reaches the target population by means of game participation and rewards, from which enhanced firm performance results (Zichermann \& Cunningham (2011).

\section{Methodology}

Several instructors implement gamification. The instructors believe in the spirit of rewards or competition as elements that help in spurring the interest and concentration of product users towards company products and services (Deterding, Dixon, Khaled \& Nacke, 2011). Examples of mechanisms that use gamification include Foursquare, Nike+, Microsoft RibbonHero, RecycleBank, Power House, and mySugr. The main aim of consumer engagement is to promote consumer engagement while striving to market the products and services of a firm. Other roles include teaching, entertaining, measuring, and improving the perceived ease of use of goods and services in business and related organizations (Deterding, Dixon, Khaled \& Nacke, 2011).

It is also noteworthy that, techniques in gamification strive towards leveraging natural desires in the target population. The desires include closure, altruism, self-expression, status, achievement, competition, mastery, learning, and socializing. According to Deterding et al. (2010), strategies in gamification use rewards to accomplish competition or desired tasks towards user engagement. Categories of rewards encompass provision of virtual currency to the users, filling of progress bars, achievement levels or badges, and earning of points. In summary, rewards towards task accomplishment become visible to other players, forming foundation from which motivation towards competition from other players is a resultant aspect.

\section{Results and Discussion}

Rapid proliferations help in the mass-market consumer software towards ensuring that video games inspire online users. Gamification trends link numerous research and concept attempts regarding human interaction, with the association involving computers. Furthermore, gamification connects games studies that include playful design, alternate reality games, and pervasive games, and serious games. It is further worth highlighting that gamification is an emerging business enterprise that has been mainstreamed to enable and change business initiatives in social contexts. In business organizations, paradigm shifts have seen companies focus on consumer experience and behavior as managers think about the contribution of social initiative-gamification link to increase knowledge levels and engagement among employees. According to Deterding et al. (2010), the paradigm shifts result in desirable business outcomes. Therefore, gamification is accompanied with enhanced performance; ranging from customer service provision to collaboration and community support. Additionally, changes that emerge from the use of gamification as a mobile service provision towards user engagement include work efficiency by saving time among online users who interact with firm products without covering much physical distance, and promotion of peaceful working environments; towards better service provision in the business sector.

As organization gain full understanding of behavior-change challenges in the quest to use games in online marketing, future implications suggest that business organizations might adopt the ever-broader ranges of gamification solutions that are emergent. Such a process would lead to relatively simple options during implementation. Furthermore, three key solutions towards the design of effective and persuasive gamification procedures are likely to remain crucial in policy implementation and user engagement (Zichermann \& Cunningham, 2011). The solutions include observation of required stages in behavior change, anticipation of challenges that face each stage, and gaming techniques that address the perceived challenges. Lastly, future prospection projects that interested firms in gamification (as a marketing strategy) might assess present challenges regarding behavior change and adopt strategies that operate in line with company priorities.

Also, uniqueness in the current IT sector has been its ability to monopolize the market share, overtaking other systems. It is this monopoly that has keeps it on the top, attracting many developers to venture in the thirdparty software products. It is also worth noting that IT operations have created an enabling environment for the 
growth of knowledge pertaining to the decreasing usability of mouse-driven monitors. As opposed to touch-screen monitors, mouse-driven monitor systems are not open and free. They arrive on the market while fully developed and, are suited for commercial purposes.

In the current IT arena, file system hierarchy is characterized by a single hierarchical directory system. This outcome implies that every process in the platform contains a single root directory. Additionally, the directory system possesses multiple hierarchies. This process, solely, depends on the drive amount possessed by the system. Each time the systems in computers boot, every drive is assigned a letter that suffices and functions as the root. In this regard, there will always be three roots, which may be labeled as C, D and F in the cases where the system supports and displays the three drives. Similarly, in cases where the computer system supports and displays two drives, there will always be two roots, which may be labeled as C and D.

In evaluating the performance of computers, it is imperative to understand the metrics or computer evaluation framework, which can then be utilized in the evaluation. Here, various approaches that are applied in the evaluation of computer processors exist. The evaluation of computer performance is now considered to be a common terminology in computer research. However, the ever-increasing complexity of computer architecture is making the process of performance evaluation complex. In the most general sense, problems in the development of appropriate computer evaluations can be considered to be oriented towards speed and accuracy. Nevertheless, the evaluations have been extended to include the uses of current computers systems whose efficiency remains desirable.

Ford's article reveals a range of issues regarding software development and project management practices. For instance, the section documenting the history and evolution of computers suggests that project management is a process whose success lies in the efforts of transitional, transactional, and transformative leaders. Through these attributes, effective project managers are likely to foster cohesiveness towards the fulfillment of a common goal. Additionally, the documentation of information regarding the evolution of computers gives critical insight to the issue of software development in such a way that it enables the audience to understand the gradual nature of the IT sector. The implication is that an organized and systematic development and implementation of software is more likely to yield more desirable outcomes.

Another section from which lessons about project management and software development are learned is "Hardware to Software." In this section, Ford affirms that aspects such as significant changes in the environmental, competitive, and legislative conditions have seen the demand fro new technologies emerge. As such, a majority of software development practices have arisen from the need to satisfy the ever-changing user needs and stakeholder preferences. Furthermore, software development is shown to have emerged because of the need for content- and context-specific applications that could meet the needs of specific individuals and organizations; ranging from fields such as business and healthcare to others such as educational and non-governmental initiatives. The section highlights further those changes in generational preferences, experiences and perceptions have driven the IT department towards the formulation of new applications. Therefore, success in project management and software development practices is documented to lie in the practice of embracing user-centeredness, rather than separate the software applications from customer-specific needs.

Besides, Ford focuses on the issue of seminars and conferences that have been held regarding issues in project management and software development. The data provided indicates that teamwork drives success during project management. This observation arises when Ford notes that members from different multicultural context are likely to share ideas regarding the changing needs of computer technology users in their respective zones. By sharing these ideas, program participants understand the need for flexibility while seeking to satisfy the needs of a dynamic world in which consumers have continually demanded new approaches to operations and problem solving. As such, it can be inferred that project management is a process requiring widespread consultations to assure the existing and potential users about the ability of the current and upcoming software developments to meet their needs. Similarly, this section implies that project management is a practice through which gradual deviations from 
traditional approaches is likely to be realized without altering the users' perceptions and believes, as an abrupt introduction of change is likely to drive away a significant number of potential customers.

At Visa Inc., the strongest message is to become a global leader in electronic card payments operation in an environment marked by user information security. This message seeks to attract customers not only from the local and regional levels but also at the global level while ensuring that the monitoring and control systems are operational and addressing any emergent issues in a timely manner to maintain the company's reputation. The second strongest message is to achieve a user base that is capable of relaying information regarding any emergent concerns in real-time. This communication or message seeks to assure the provision of an effective platform from which Visa's customers can air their views or raise concerns and receive a near immediate response from the department charged with user information security. The third strongest message is to secure a well-equipped troop whose unending effort to curb dangers arising from unseen or unknown cyber-attacks will be characterized by interdepartmental and inter-agency collaboration. The implication is that customers are expected to gain an insight into Visa's internal and external mechanisms related to expertise provision towards assuring confidence about the security of their personal informal - as they continue to seek or use the company's services.

\section{Conclusion}

In conclusion, this paper has focused on the concept of computer evolution and the emergence of new operations in the IT sector. Specifically, What Is Code? an article by Ford (2015), has been used to offer critical insight regarding some of the events characterizing the current technology-driven world. The article indicates that the users' needs are ever-changing. Given that organizations understand behavior-change challenges while seeking to use gamification mechanics towards controlling consumer behaviors that yield enhanced performance, the firms might also adopt the ever-broader ranges of gamification solutions that are emergent; leading to a relatively simple marketing; courtesy of the evolution of gamification as a computer science concept.

\section{References}

[1] Baptista, G. and Oliveira, T. (2017) 'Why so serious? Gamification impact in the acceptance of mobile banking services', Internet Research, vol. 27, no. 1, pp. 118-139. http://dx.doi.org/10.1108/IntR-102015-0295

[2] Bittner, J.V. and Schipper, J. (2014) 'Motivational effects and age differences of gamification in product advertising', Journal of Consumer Marketing, vol. 31, no. 5, pp. 391-400. http://dx.doi.org/10.1108/JCM-04-2014-0945

[3] Conejo, F. (2014) 'Loyalty 3.0: How to revolutionize customer and employee engagement with big data and gamification?', Journal of Consumer Marketing, vol. 31, no. 1, pp. 86-87.

[4] Dekker, A.H. (2005) 'Conceptual Distance in Social Network Analysis', Journal of Social Structure, vol. 6, no. 3.

[5] Deterding, S, Dan, D., Rilla, K. and Lennart, N. (2011) 'From game design elements to gamefulness: defining gamification', Proceedings of the 15th International Academic Mind Trek Conference: Envisioning Future Media Environments, pp. 9-15.

[6] Dignan, A. (2011) Game Frame: Using Games as a Strategy for Success, New York: Free Press.

[7] Deterding, S., Dixon, D., Khaled, R. \& Nacke, L. (2011). From game design elements to gamefulness: Defining "Gamification". Proceedings from MindTrek '11. Tampere, Finland: ACM

[8] Ford, P. (June 11, 2015). "What Is Code?" BusinessWeek. Retrieved on September 7, 2019 from http://www.bloomberg.com/graphics/2015-paul-ford-what-is-code/

[9] Zichermann, G. \& Cunningham, C. (2011). Gamification by Design: Implementing Game Mechanics in Web and Mobile Apps, Sebastopol, CA: O'Reilly Media 